\title{
Accuracy of a hand-held lactate meter in measuring umbilical cord blood lactate at all lactate levels
}

\author{
Seng C. Chua ${ }^{*}$, May Y. W. Wong, Tina Y. Su, Mifanwy Reece \\ Obstetrics and Gynaecology, Westmead Hospital, Sydney, New South Wales, Australia \\ Email: 라huasc@gmail.com \\ Received 14 December 2013; revised 7 January 2014; accepted 14 January 2014 \\ Copyright (C) 2014 Seng C. Chua et al. This is an open access article distributed under the Creative Commons Attribution License, \\ which permits unrestricted use, distribution, and reproduction in any medium, provided the original work is properly cited. In accor- \\ dance of the Creative Commons Attribution License all Copyrights (c) 2014 are reserved for SCIRP and the owner of the intellectual \\ property Seng C. Chua et al. All Copyright (C) 2014 are guarded by law and by SCIRP as a guardian.
}

\section{ABSTRACT}

Objective: Fetal scalp lactate has largely replaced pH analysis to assess intrapartum hypoxia. Many obstetrics units use hand-held lactate meters to measure umbilical blood because of its affordability and ease of use. We sought to investigate the agreement of Lactate Pro ${ }^{\mathrm{TM}}$ with a reference method blood gas analyser and to determine its usefulness with a recommended cutoff value of $4.8 \mathrm{mmol} / \mathrm{L}$. Methods: Prospective study carried out at a tertiary institution where 237 arterial and 233 venous samples from umbilical cords of 16 elective caesarean and 285 emergency deliveries were measured using Lactate Pro ${ }^{\mathrm{TM}}$ and ABL735 Sesries AcidBase analyser. Limits of agreement were analysed using Bland-Altman plots. Results: Lactate Pro ${ }^{\mathrm{TM}}$ differentiated fewer deliveries as "high risk" $(\geq 4.8 \mathrm{mmol} / \mathrm{L})$ and more as "low risk" ( $<2.2 \mathrm{mmol} / \mathrm{L})$. Limits of agreement for lactate values (as measured by Lactate Pro $^{\mathrm{TM}}$ ) were $-1.46-0.97 \mathrm{mmol} / \mathrm{L}$ for arterial lactate levels $<4.8 \mathrm{mmol} / \mathrm{L}$ and $-3.21-0.88 \mathrm{mmol} / \mathrm{L}$ for arterial lactate levels $\geq 4.8 \mathrm{mmol} / \mathrm{L}$. Conclusion: There was a poorer agreement between the two devices at higher lactate values. Lactate Pro ${ }^{\mathrm{TM}}$ underestimates by up to $3.2 \mathrm{mmol} / \mathrm{L}$; a $4.8 \mathrm{mmol} / \mathrm{L}$ reading may actually signify a lactate level of $8.0 \mathrm{mmol} / \mathrm{L}$, indicating severe metabolic acidosis. We caution the use of this device in assessing fetal lactate levels.

\section{KEYWORDS}

Agreement; Blood Gas Analyser; Comparison; Lactate; Umbilical Cord Blood

\section{INTRODUCTION}

In the presence of a nonreassuring cardiotocogaph (CTG), ${ }^{*}$ Corresponding author. fetal blood sampling (FBS) with $\mathrm{pH}$ assessment continues to play an important role in providing a more specific measure of fetal status than CTG alone since its introduction by Saling in 1967.

A $\mathrm{pH}<7.20$ was chosen as cut-off value to recommend intervention. However, there are several limitations using $\mathrm{pH}$ readings including low specificity in separating transient respiratory acidosis from the more deleterious metabolic acidosis [1-3].

Since the observational study by White et al. in 2010 [4] which found improved perinatal outcomes, independent of obstetric intervention, many Australian maternity hospitals have introduced routine umbilical cord blood lactate measurement following all births. For maternity units where formal umbilical cord blood lactate measurement using a standard blood gas analyser is not a feasible option, lactate analysis using a hand held meter is often performed in its place for a fraction of the cost $[5,6]$. The accuracy of these portable hand held meter has not been tested rigorously in neonatal settings. If these lactate measurements are not accurate, there are important implications for current practices and future medico-legal interactions. The additional implication of such concerns involves FBS for lactate measurement, the results of which direct clinical interventions such as continuing labour, or more urgent delivery. In contrast to studies of $\mathrm{pH}$ values, there have not been many "real time" studies directly using fetal blood to validate the agreement of these devices with reference methods [7-9]. Furthermore, previous studies did not include samples with lactate concentration high enough to detect the proportional negative bias.

The aim of this study is to determine the concordance between bedside measurement of lactate using Lactate Pro and a reference blood gas analyser in low and high risk deliveries where lactate levels often surpass the 4.8 $\mathrm{mmol} / \mathrm{L}$ threshold. 


\section{METHODS}

A prospective study was carried out between June 2008 and April 2009 in Westmead Hospital, Sydney, Australia. Westmead Hospital has a tertiary-level maternity unit where over 5000 delivers take place each year. Umbilical cords from 285 babies born at 26 - 42 weeks gestation were collected for all deliveries which warranted neonatal blood sampling at birth; these included non-elective caesareans, instrumental deliveries, deliveries where intrapartum scalp lactate was measured, deliveries where a paediatrician was requested, and complications such as meconium stained liquor, shoulder dystocia, APGAR $<7$ at one minute or baby requiring resuscitation other than tactile stimulation occurred. An additional 16 cord blood samples were taken from 16 elective caesarean sections to give a more even spread of lactate values.

Each umbilical cord was double clamped immediately after delivery. Samples were collected and measured by a single independent researcher during working hours and by obstetricians, obstetric registrars and midwives after hours. Arterial samples were drawn from the umbilical artery followed by venous samples drawn from the umbilical vein using 23 gauge needles into pre-labelled 1 $\mathrm{cm}^{3}$ pre-heparinised syringes and kept on ice. We have previously established that lactate remains stable over ice [10].

One Lactate Pro hand-held device and one Radiometer ABL735 Series Acid-Base analyser was used (Table 1). The arterial and venous samples were analysed at the same time within 10 minutes of delivery. Samples were confirmed as being arterial or venous by comparing the $\mathrm{pH}$ and $\mathrm{pO}_{2}$ values of paired venous and arterial samples from the Blood Gas Analyser.

Table 1. Specifications for lactate measurement devices.

\begin{tabular}{ccc}
\hline & Lactate Pro & $\begin{array}{c}\text { ABL 735 Series } \\
\text { Acid-Base Analyser }\end{array}$ \\
\hline Manufacturer & $\begin{array}{c}\text { Arkray KDK, } \\
\text { Japan } \\
\text { Nil other }\end{array}$ & $\begin{array}{c}\text { Radiometer Copenhagen, } \\
\text { Denmark } \\
\text { Co-oximetry, electrolyte and } \\
\text { metabolite measurement } \\
\text { Potentiometry and } \\
\text { Amperometry }\end{array}$ \\
Sample Volume (uL) & 5.0 & 75.0 \\
$\begin{array}{c}\text { Analysis time (s) } \\
\text { Measurement Range } \\
\text { (mmol/L) }\end{array}$ & $60.8-23.3$ & 80 \\
Quality control & $\begin{array}{c}\text { Calibration strip } \\
\text { and Check strip }\end{array}$ & $\begin{array}{c}\text { Calibrated every } 4 \text { h, according } \\
\text { to the manufacturer's } \\
\text { recommendations }\end{array}$ \\
Data output & No & Yes \\
Weight & $\sim 50 \mathrm{~g}$ & 30 kg \\
\hline
\end{tabular}

All data was recorded in Microsoft Excel. Agreement of the point of care (POC) device with the ABL735 Series Acid Base analyser reference method was assessed by Bland and Altman plots with mean difference and limits of agreement (estimated by mean difference \pm 1.96 standard deviation of the differences and provide an interval within which $95 \%$ of differences between measurements by the two methods are expected to lie). In addition, limits of agreement for the different cut off values of 4.8 and $4.0 \mathrm{mmol} / \mathrm{L}$ were studied.

As this study conforms to the standards established by the NHMRC for ethical quality review, ethics approval was not sought. All patients gave oral consent for the procedure.

\section{RESULTS}

A total of 301 umbilical cords [16 elective caesarean, 285 high risk) were collected. Arterial and venous samples were collected. Insufficient volume samples were not analysed. 237 arterial and 233 venous samples were measured. Arterial values for lactate ranged from 0.9 $17.0 \mathrm{mmol} / \mathrm{L}$ (ABL735) and 1.4 - $14.3 \mathrm{mmol} / \mathrm{L}$ (Lactate Pro) whilst venous values for lactate ranged from 0.7-18 $\mathrm{mmol} / \mathrm{L}$ (ABL735) and 0.8 - $13.8 \mathrm{mmol} / \mathrm{L}$ (Lactate Pro) (Figures 1 and 2).

Lactate Pro differentiated fewer deliveries to the "high risk" group (lactate result $\geq 4.8 \mathrm{mmol} / \mathrm{L}$ ) and more deliveries to the "low risk" group (lactate result $<2.2$ $\mathrm{mmol} / \mathrm{L}$ ) for Lactate Pro, as compared to the ABL735 Series Acid-Base analyser, irrespective of arterial or venous samples. Both groups had similar number of deliveries in the "intermediate risk" group (lactate result 2.2

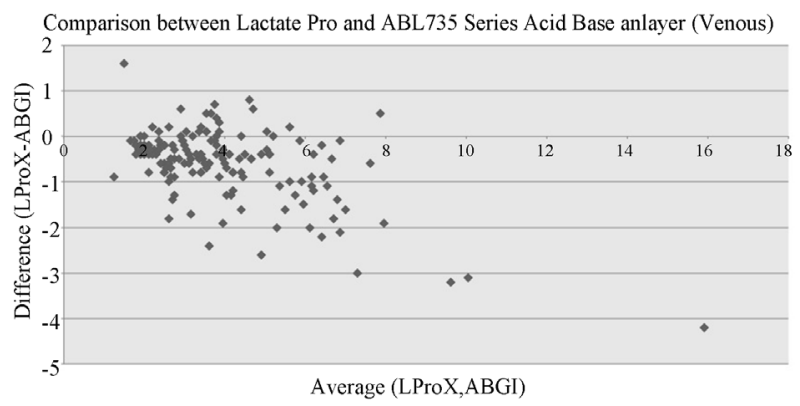

Figure 1. Demonstrates the level of agreement on Bland-Altman plots which show linear regression analysis (mean difference with 2 SD) between Lactate Pro compared with the reference ABL735 Series Acid-Base analyser for venous values. The Y-axis represents difference between lactate values of the two devices compared for each sample, and the $\mathrm{X}$-axis represents the mean of the lactate values from the two devices from the corresponding sample. The closer the cluster is around the value of 0.00 on the Y-axis (difference) the higher the level of agreement there is between the two devices compared. Lactate values are given in Système International units $(\mathrm{mmol} / \mathrm{L})$; to convert to conventional units (mg/dL), divide by 0.1110 . 


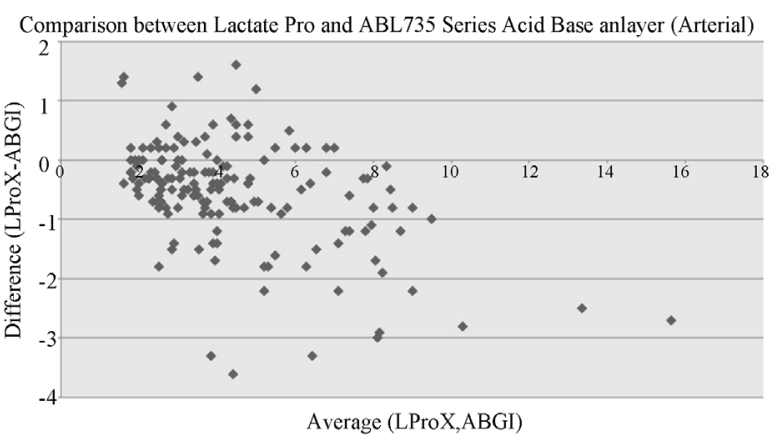

Figure 2. Demonstrates the level of agreement on Bland-Altman plots which show linear regression analysis (mean difference with 2 SD) between Lactate Pro compared with the reference ABL735 Series Acid-Base analyser for arterial values. The Y-axis represents difference between lactate values of the two devices compared for each sample, and the $\mathrm{X}$-axis represents the mean of the lactate values from the two devices from the corresponding sample. The closer the cluster is around the value of 0.00 on the Y-axis (difference) the higher the level of agreement there is between the two devices compared. Lactate values are given in Système International units $(\mathrm{mmol} / \mathrm{L})$; to convert to conventional units (mg/dL), divide by 0.1110 .

- $4.7 \mathrm{mmol} / \mathrm{L}$ ), again, irrespective of arterial or venous samples (Table 2).

A mean difference of 0.55 to $0.60 \mathrm{mmol} / \mathrm{L}$ in lactate readings were found between the two devices. Lactate Pro device recorded consistently lower values of lactate compared with ABL735 Series Acid-Base analyser. Limits of agreement between the two methods of measurement for arterial samples was $-2.3-1.2 \mathrm{mmol} / \mathrm{L}$ when Lactate Pro was compared to ABL735 Series Acid-Base analyser. Similar variance was found with venous values where the limits of agreement were $-2.2-1.0 \mathrm{mmol} / \mathrm{L}$ (Table 3).

Limits of agreement were calculated for specific cut offs. For low lactate values $(<4.8 \mathrm{mmol} / \mathrm{L})$, the limits of agreement were -1.46 to $0.97 \mathrm{mmol} / \mathrm{L}$ and -1.29 to 0.62 $\mathrm{mmol} / \mathrm{L}$ for arterial and venous samples respectively. Limits of agreement for high lactate values $(\geq 4.8$ $\mathrm{mmol} / \mathrm{L}$ ) were -3.21 to $0.88 \mathrm{mmol} / \mathrm{L}$ and -3.18 to 0.76 $\mathrm{mmol} / \mathrm{L}$ for arterial and venous samples respectively (Table 3).

\section{DISCUSSION}

Lactate is a suitable alternative to $\mathrm{pH}$ analysis as it can provide discrimination between respiratory and metabolic acidosis. Metabolic acidemia develops when oxygen deprivation is of sufficient duration and magnitude to require anaerobic metabolism for cellular energy needs [11,12], of which lactic acid is the main organic acid contributing to the base deficit [13]. Various studies have identified significant correlations between umbilical artery lactate values and early indicators of neonatal condition, including Apgar scores, umbilical artery $\mathrm{pH}$ values
Table 2. Analysis of Lactate Pro and ABL735 Series Acid Base anlayser values into risk categories according to clinical lactate values.

\begin{tabular}{ccc}
\hline Risk Category & $\begin{array}{c}\text { Lactate Pro } \\
\text { (arterial, venous) }\end{array}$ & $\begin{array}{c}\text { ABL735 Series Acid } \\
\text { Base Analyser } \\
\text { (arterial, venous) }\end{array}$ \\
\hline Low $(<2.2 \mathrm{mmol} / \mathrm{L})$ & 23,31 & 14,16 \\
$\begin{array}{c}\text { Intermediate } \\
(2.2-4.7 \mathrm{mmol} / \mathrm{L})\end{array}$ & 96,95 & 97,98 \\
High $(\geq 4.8 \mathrm{mmol} / \mathrm{L})$ & 45,37 & 53,48 \\
\hline
\end{tabular}

Table 3. Comparison of mean differences limits of agreement between arterial and venous samples.

\begin{tabular}{ccc}
\hline & Arterial & Venous \\
\hline $\begin{array}{c}\text { Mean difference (mmol/L) } \\
\text { (Lactate Pro-ABL735) }\end{array}$ & -0.5518 & -0.5963 \\
SD difference & 0.8833 & 0.7780 \\
limits of agreement & $-2.3-1.2$ & $-2.2-1.0$ \\
$\begin{array}{c}\text { Limits of agreement at Lactate }<4.8 \\
\text { (Lactate Pro) }\end{array}$ & $-1.8-1.02$ & $-1.62-0.70$ \\
$\begin{array}{c}\text { Limits of agreement at Lactate } \geq 4.8 \\
\quad \text { (Lactate Pro) }\end{array}$ & $-3.14-1.42$ & $-3.34-1.21$ \\
$\begin{array}{c}\text { Limits of agreement at Lactate }<4.2 \\
\quad \text { (Lactate Pro) }\end{array}$ & $-1.85-0.96$ & $-1.58-0.70$ \\
Limits of agreement at Lactate $\geq 4.2$ \\
$\quad$ (Lactate Pro)
\end{tabular}

and umbilical artery base excess values [14-19]. Furthermore, cord blood lactate levels collected at delivery have been demonstrated to be equivalent to full blood gas analyses in predicting NICU admission, meconium aspiration, idiopathic respiratory distress syndrome, assisted ventilation, neurological abnormality, neonatal encephalopathy, HIE and neonatal death $[5,16,20]$. Recently published data based on a large population study of 21,182 term neonates showed that cord blood lactate and the level of neonatal resuscitation was the best predictor of HIE of 47 different predictive models evaluated [20]. In fact, determination of lactate in blood from the fetus's scalp during labour has been extensively studied since the 1970s [3,21-27]. These observational studies have shown that lactate analysis has similar or better predictive properties compared with $\mathrm{pH}$ analysis in the identification of short term neonatal morbidity. Specifically, it is superior for Apgar score $<4$ at 5 minutes as well as in relation to moderate-to-severe HIE $[27,28]$. In a recent meta-analysis [29] of randomized control trials, fetal scalp lactate testing was shown to be an accurate and reliable alternative to fetal scalp $\mathrm{pH}$ testing and more likely to be successfully undertaken. There are several other properties of lactate which make it an attractive biomarker; lactate has a relatively long half-life and corrects more slowly than $\mathrm{pH}[30,31]$, allowing cumulative hy- 
poxia to be measured [16]. In addition, lactate rises before $\mathrm{pH}$ drops in peripheral tissues [16] enabling earlier detection of hypoxia (1).

Several methods are available for lactate testing including laboratory analyser methods; blood gas analyzers and hand-held lactate meters. Laboratory methods for measuring plasma lactate are based on enzymatic methods (lactate oxidase) with colorimetric detection. Laboratory based methods, because of the delayed turn around time, are not ideal when rapid patient decision making is required. In addition, samples are required to be sent on ice because of the labiality of lactate in blood specimens. Blood gas analysers can provide near patient testing for lactate but they are not always readily available in obstetric units. Furthermore, blood gas analysers require a sample volume that is often not achievable with fetal blood sampling.

Conversely, hand-held lactate meters offer greater ease of use, shorter time to result, smaller blood sample sizes, and lower cost compared to blood gas analysers. It has the potential to be used in rural and remote settings where laboratory technology may be unavailable due to costs and /or operator skill [32,33]. A significant practical advantage is that the machines require less blood and thus fewer scalp incisions [34]. The most commonly used device is the Lactate Pro [ARKRAY, Kyoto, Japan] [32]. An earlier study sponsored by Lactate Pro showed a strong correlation between Lactate Pro and existing blood gas analysers up to lactate levels of $18 \mathrm{mmol} / \mathrm{L}$. Nordstrom et al. compared the performance of Lactate Pro to a reference method, the Vitros LAC slide assay, using 120 samples obtained from the umbilical vein and artery. They determined that mean Lactate Pro values were $0.4 \mathrm{mmol} / \mathrm{L}$ lower than the lactate reference method over a range of 2.1 to $5.3 \mathrm{mmol} / \mathrm{L}$ [8]. However their study did not include samples with lactate concentration high enough to detect the proportional negative bias. In the first part of the study, we found insignificant differences between Lactate Pro and blood gas analyser at low lactate values [10]. Although the manufacturer's specifications indicate Lactate Pro measures lactate concentrations in whole blood between 0.8 and $23 \mathrm{mmol} / \mathrm{L}$, few studies have explored its accuracy at such high lactate levels. Lactate levels should also be interpreted with caution as Westgren et al. (1995) found the specificity of lactate to be $0 \%-44 \%$ when predicting various neonatal outcome measures. Raised lactate is not specific of increased anaerobic metabolism [6] but may also arise from maternal glucose administration, beta-mimetic drugs and the fetal intrapartum catecholamine surge.

In previous studies comparing different Lactate measuring devices, Pyne et al. (2000) found limits of agreement to be -1.83 to $2.09 \mathrm{mmol} / \mathrm{L}$ between Lactate Pro and blood gas analyser for lactate values of 1 - $18 \mathrm{mmol} / \mathrm{l}$ $(r=0.98)$ in elite athletes [32]. The limits of agreement were validated in a study by Tanner et al. 2010 where they were $\pm 2.1 \mathrm{mmol} / \mathrm{L}$ [33]. Our previous study showed there were good levels of agreement at low lactate levels in elective Caesarean sections [10]. The between-run coefficient of variation was $3 \%-5 \%[8,35]$ and may be as high as $8.4 \%$ in our study, which related to neonates at risk of birth hypoxia. The Bland-Altman plot suggests an association between the difference in readings from Lactate Pro and ABL735 Series Acid-Base analyser. Lactate Pro device recorded consistently lower values of lactate compared with ABL735 Series Acid-Base analyser. We found that Lactate Pro underestimates values by up to 2.3 $\mathrm{mmol} / \mathrm{L}$ and overestimates values by up to $1.2 \mathrm{mmol} / \mathrm{L}$ when compared to ABL735 Series Acid-Base analyser. For example, a reading of $4.0 \mathrm{mmol} / \mathrm{L}$ could mean a level of $2.8 \mathrm{mmol} / \mathrm{L}$, providing reassurance, but could also mean a level of $7.2 \mathrm{mmol} / \mathrm{L}$ which would signify significant metabolic acidosis in the newborn. Although our results only deal with neonatal umbilical blood sampling, we can extrapolate that using Lactate Pro for fetal scalp lactate sampling will have similar discrepancies.

A Cochrane systematic review meta-analysis recommended that the cut-off for intervention needs to take into consideration the device used [29]. The present cut off value of $4.8 \mathrm{mmol} / \mathrm{L}$ in obstetrics units worldwide is based on a randomised control trial conducted by Kruger in 1999 where it represented the $75^{\text {th }}$ percentile. They found it led to a similar rate of intervention as a $\mathrm{pH}$ of 7.2. While we acknowledge the validity of the study as it measures fetal scalp lactate directly, our study on newborn lactate using the same device urge us to be cautious with higher lactate levels. In our study, we found that at a lactate level of $4.8 \mathrm{mmol} / \mathrm{L}$, the limits of agreement were extremely wide and could lead to systemic underestimation. For example, a $4.8 \mathrm{mmol} / \mathrm{L}$ Lactate Pro reading could actually reflect a lactate level of $8.0 \mathrm{mmol} / \mathrm{L}$ (limits of agreement -3.21 to $0.88 \mathrm{mmol} / \mathrm{L}$ ). In our study, the $75^{\text {th }}$ percentile reflected an arterial lactate value of 5.0 $\mathrm{mmol} / \mathrm{L}$, demonstrating a similar population group to the Kruger study. We searched for a lactate level which could provide us with more reassurance. Upon re-analysing samples from high-risk deliveries, we found the $68 \%$ confidence interval for lactate levels $\geq 4.2 \mathrm{mmol} / \mathrm{L}$ resulted in limits of agreement to be -1.85 to 0.37 . This means a Lactate Pro reading of $4.2 \mathrm{mmol} / \mathrm{L}$ could mean $6.0 \mathrm{mmol} / \mathrm{L}$, an acceptable level during delivery, but we can only be $68 \%$ confident. This is supported by the cutoff value of $4.2 \mathrm{mmol} / \mathrm{L}$ recommended following an observational study by Allen 2004 [36] (Boeringer, Mannheim, East Sussex, UK) and a report by Smith 1983 [25]. The determination of an optimum cut off level is a delicate balance as lactate levels below $4.8 \mathrm{mmol} / \mathrm{L}$ will cause a large number of false negatives [27] whilst levels above 
$4.8 \mathrm{mmol} / \mathrm{L}$ can result in HIE. Therefore the cut-off lactate value must be considered specifically for the lactate meter in use. One option for those developing guidelines for their institution may be to base their recommendations on values used in studies performed with the specific lactate meter in use at the hospital's birthing facility. Luttkus and colleagues evaluated three lactate biosensors and one test-strip device (Lactate Pro) regarding precision in serial and repetitive measurements in over 1350 samples of fetal whole blood. Blood tonometry which simulated conditions of fetal hypoxia demonstrated an increase of SD and coefficient of variation in all devices, which reinforced how users should be aware of the errors associated with different devices before a clinical decision is made [37].

This raises the question of whether we should be attempting to take larger fetal scalp samples for ABG analysis instead. Westgren et al. performed a randomized multi-center control trial enrolling 341 cases in which the fetal heart rate patterns were ominous $(\mathrm{pH}$ determined in 169 and lactate in 172) who had undergone FBS. No significant difference was found between the two groups with regards to mode of delivery or neonatal outcome [31]. They concluded that lactate is comparable to $\mathrm{pH}$ in regards to intrapartum fetal monitoring. He also showed significantly fewer failures in sampling with lactate analysis (odds ratio 16.1, 95\% confidence interval 5.8 to 44.7). The limited size of the study however, meant it could not compare metabolic acidaemia at birth or HIE. Kruger et al. performed a larger retrospective study of 1709 patients (pH determined in 1221, lactate in 814, and both in 326) who had undergone FBS. They reported that scalp lactate of $4.0 \mathrm{mmol} / \mathrm{L}$ was predictive of an Apgar < 7 at $1 \mathrm{~min}$ and $4.4 \mathrm{mmol} / \mathrm{L}$ was predictive of any level of HIE. They concluded that the scalp lactate level had a better sensitivity than scalp $\mathrm{pH}$ as a marker for neonatal neurologic disability [27]. By drawing ROC curves, these authors calculated areas under curves which were significantly in favor of lactate samplings as compared to $\mathrm{pH}$ in the prediction of an Apgar score $<4$ at 5 min and of cerebral palsy.

One of the strengths of our study includes having one independent researcher for collection of samples during working hours to ensure consistency and reliable technique. Furthermore this is a "real time" study directly using neonatal blood from a range of deliveries ranging from elective caesareans to emergency deliveries; providing a scope that would be encountered in clinical practice. The limitations of our study include using cord blood data for analysis. We use this data to infer correlations with fetal scalp sampling. Umbilical cord blood is known to be generally more acidic than fetal scalp blood as the fetus becomes gradually more acidic during the course of labor and delivery [26]. However, fetal blood is very similar in characteristics and composition to umbilical cord blood (low partial oxygen pressures and high hematocrit).

\section{Conclusion}

Lactate machines were originally developed for monitoring lactate levels following exercise or sporting activities in order to enhance training regimes. Some of these meters have migrated from a sports application to use in a hospital setting without significant change in their design. It is important that before a POC lactate method is implemented for fetal blood lactate testing, the decisionmaking criteria implemented be adjusted according to the device used. This study suggests that perhaps a lower cut-off reading for POC machines of $4.2 \mathrm{mmol} / \mathrm{L}$ may be needed in order to attain an acceptable limit of agreement. This may improve its clinical utility and avoid missing false negatives. With the emergence of new hand-held hospital lactate meters e.g. StatStrip Lactate, it is important to conduct validation studies prior to determining requirements of a meter-specific cut-off value. A systemic overestimation of lactate levels may lead to unnecessary intervention. More deleteriously, a systemic underestimation of lactate levels may result in delayed intervention, compromising fetal outcome.

\section{Acknowledgements}

We wish to thank Karen Byth, statistician at Westmead Hospital for her contribution to our data analysis and all Birth Unit Midwives and after hours medical staff.

\section{Declaration of Interest}

There are no conflicts of interest declared for this study.

\section{REFERENCES}

[1] Nordstrom, L. (2004) Fetal scalp and cord blood lactate. Best Practice \& Research Clinical Obstetrics and Gynaecology, 18, 467-476. http://dx.doi.org/10.1016/j.bpobgyn.2004.02.006

[2] Nordstrom, L II and Westgren, M. (1996) Fetal monitoring with lactate. Baillieres Clinical Obstetrics \& Gynaecology, 10, 225-242. http://dx.doi.org/10.1016/S0950-3552(96)80035-6

[3] Saling, E.S.D. (1967) Biochemical supervision of the foetus during labour. Journal of Obstetrics \& Gynaecology of the British Commonwealth, 74, 799-811. http://dx.doi.org/10.1111/j.1471-0528.1967.tb15561.x

[4] White, C.R.D.D., Henderson, J.J., Kohan, R., Newnham, J.P. and Pennell, C.E. (2010) Benefits of introducing universal umbilical cord blood gas and lactate analysis into an obstetric unit. Australian and New Zealand Journal of Obstetrics and Gynaecology, 50, 318-328. http://dx.doi.org/10.1111/j.1479-828X.2010.01192.x 
[5] Westgren, W.M.D.M., Horal, M., Ingemarsson, I., Kublickas, M., Shimojo, N. and Nordström, L. (1995) Routine measurements of umbilical artery lactate levels in the prediction of perinatal outcome. American Journal of $\mathrm{Ob}$ stetrics and Gynecology.

[6] Pennell, C.E.T.M. (1999) A new method for rapid measurement of lactate in fetal and neonatal blood. Australian and New Zealand Journal of Obstetrics and Gynaecology, 39, 227-233. http://dx.doi.org/10.1111/j.1479-828X.1999.tb03379.x

[7] Ridenour, R.G.R., Brost, B. and Karon, B. (2008) Comparison and validation of point of care lactate meters as a replacement for fetal $\mathrm{pH}$ measurement. Clinical Biochemistry, 41, 1461.

http://dx.doi.org/10.1016/j.clinbiochem.2008.08.088

[8] Nordstrom, L.C.S., Roy, A. and Arulkumaran, S. (1998) Quality assessment of two lactate test strip methods suitable for obstetric use. Journal of Perinatal Medicine, 26, 83-88. http://dx.doi.org/10.1515/jpme.1998.26.2.83

[9] Luttkus, A.F.C., Sehouli, J., Stupin, J. and Dudenhausen, J.W. (2010) Technical performance of lactate biosensors and a test-strip device during labour. Zeitschrift für $\mathrm{Ge}$ burtshilfe und Neonatologie, 214, 62-67. http://dx.doi.org/10.1055/s-0030-1249641

[10] Su, T.Y.R.M. and Chua, S.C. (2013) Lactate study using umbilical cord blood: Agreement between Lactate Pro hand-held devices with blood gas analyser and evaluation of lactate stability over time. Australian and New Zealand Journal of Obstetrics and Gynaecology.

[11] Uzan, S.B.N., Verstraete, L., Mathieu, E. and Bréart, G. (2003) Acid base balance in the fetus during labor: Pathophysiology and exploration methods. Journal of Obstetrics \& Gynecology and Reproductive Biology (Paris), 32, S68-S78.

[12] Borruto, F.C.C. and Treisser, A. (2008) Prevention of cerebral palsy during labour: Role of fetal lactate. Archives of Gynecology and Obstetrics, 278, 17-22. http://dx.doi.org/10.1007/s00404-007-0531-1

[13] Nordstrom, L. (2001) Lactate measurements in scalp and cord arterial blood. Current Opinion in Obstetrics and Gynecology, 13, 141-145. http://dx.doi.org/10.1097/00001703-200104000-00008

[14] Watt, W.F.T.K. and Yeo, G.S.H. (2002) Umbilical cord lactate: A preliminary study of 130 term babies. Singapore Journal of Obstetrics and Gynaecology, 33, 42-48.

[15] Gjerris, A.C.S.-J.J., Jørgensen, J.S., Bergholt, T. and Nickelsen, C. (2008) Umbilical cord blood lactate: A valuable tool in the assessment of fetal metabolic acidosis. The European Journal of Obstetrics \& Gynecology and Reproductive Biology, 139, 16-20. http://dx.doi.org/10.1016/j.ejogrb.2007.10.004

[16] Chou, Y.H.T.Y.K. and Wang, P.J. (1998) Clinical application of the measurement of cord plasma lactate and pyruvate in the assessment of high risk neonates. Acta Paediatrica, 87, 764-768. http://dx.doi.org/10.1111/j.1651-2227.1998.tb01744.x

[17] Suidan, J.S.W.J. and Young, B.K. (1984) Placenta contribution to lactate production by the human fetoplacental unit. American Journal of Pathology, 4, 306-309. http://dx.doi.org/10.1055/s-2007-1000027

[18] Ruth, V.J.R.K. (1988) Perinatal brain damage: Predictive value of metabolic acidosis and the Apgar score. British Medicine Journal, 297, 24-27. http://dx.doi.org/10.1136/bmj.297.6640.24

[19] Abessolo, F.O.N.J., Meye, J.F., Yangou, J.M., Lemamy, G.J. and Ngou-Milama, E.J. (2009) Fetal distress: Information provided by lactate levels and antioxidant status, compared with the Apgar score. Sante, 19, 15-19.

[20] White, C.R.H.D.D., Henderson, J.J., Kohan, R., Newnham, J.P. and Pennell, C.E. (2012) Accurate prediction of hypoxic-ischaemic encephalopathy at delivery: A cohort study. The Journal of Maternal-Fetal \& Neonatal Medicine, 25, 1653-1659. http://dx.doi.org/10.3109/14767058.2011.653421

[21] Wiberg-Itzel, E.L.C., Norman, M., Herbst, A., Prebensen, D., Hansson, A., Bryngelsson, A.L., Christoffersson, M., Sennström, M., Wennerholm, U.B. and Nordström, L. (2008) Determination of $\mathrm{pH}$ or lactate in fetal scalp blood in management of intrapartum fetal distress: Randomised controlled multicentre trial. BMJ, 336, 1284-1287. http://dx.doi.org/10.1136/bmj.39553.406991.25

[22] Saugstad, O. (2002) Is lactate a reliable indicator of tissue hypoxia in the neonatal period? Acta Paediatrics, 91, 1719. http://dx.doi.org/10.1111/j.1651-2227.2002.tb01633.x

[23] Yoshioka, T.R.J. (1970) Correlation of fetal scalp blood $\mathrm{pH}$, glucose, lactate and pyruvate concentration with cord blood determinations at time of delivery and cesarean section. Journal of Perinatal Medicine, 5, 63-68.

[24] Eguiluz, A., Lp, B.A., McPherson, K., Parrilla, J.J. and Abad, L. (1983) The use of intrapartum fetal blood lactate measurements for the early diagnosis of fetal distress. American Journal of Obstetrics and Gynecology, 147, 949-954.

[25] Smith, N.C.S.W. and Sharp, F. (1983) Fetal scalp blood lactate as an indicator of intrapartum hypoxia. British Journal of Obstetrics and Gynaecology, 90, 821-831. http://dx.doi.org/10.1111/j.1471-0528.1983.tb09322.x

[26] Nordström, L.II, Kublickas, M., Persson, B., Shimojo, N. and Westgren, M. (1995) Scalp blood lactate-A new test strip method for monitoring fetal well-being in labour. British Journal of Obstetrics and Gynaecology, 102, 845849. http://dx.doi.org/10.1111/j.1471-0528.1995.tb10878.x

[27] Kruger, K.H.B., Blennow, M., Kublickas, M. and Westgren, M. (1999) Predictive value of fetal scalp blood lactate concentration and $\mathrm{pH}$ as markers of neurologic disability. American Journal of Obstetrics and Gynecology, 181, 1072-1078. http://dx.doi.org/10.1016/S0002-9378(99)70083-9

[28] Ramanah, R.M.R., Riethmuller, A., Maillet, D. and Schaal, J.P. (2005) Value of fetal scalp lactate sampling during labour: A comparative study with scalp pH. Gynecology Obstetrique \& Fertilite, 33, 107-119. http://dx.doi.org/10.1016/j.gyobfe.2005.01.004

[29] East, C.E.L.L., Sheehan, P., Henshall, N.E. and Colditz, P.B. (2010) Intrapartum fetal scalp sampling for fetal as- 
sessment in the presence of a non-reassuring fetal heart rate trace. Cochrane Database of Systematic Reviews, 3, CD006174.

[30] Tuffnell, D.H.W. and Wilkinson, K. (2006) How long does a fetal scalp blood sample take? BJOG, 113, 332-334. http://dx.doi.org/10.1111/j.1471-0528.2006.00859.x

[31] Westgren, M.K.K., Ek, S., Grunevald, C., Kublickas, M., Naka, K., Wolff, K. and Persson, B. (1998) Lactate compared with $\mathrm{pH}$ analysis at fetal scalp blood sampling: A prospective randomised study. British Journal of Obstetrics and Gynaecology, 105, 29-33. http://dx.doi.org/10.1111/j.1471-0528.1998.tb09346.x

[32] Pyne, D.B.T., Martin, D. and Logan, A. (2000) Evaluation of the lactate pro blood lactate analyser. European Journal of Applied Physiology, 82, 112-116. http://dx.doi.org/10.1007/s004210050659

[33] Tanner, R.F.K. and Ross, M. (2010) Evaluation of three portable blood lactate analysers: Lactate Pro, lactate scout and lactate plus. European Journal of Applied Physiology, 109, 551-559. http://dx.doi.org/10.1007/s00421-010-1379-9
[34] Westgren, M.K.K., Ek, S., Grunevald, C., Kublickas, M., Naka, K., Wolff, K. and Persson, B. (1998) Lactate compared with $\mathrm{pH}$ analysis at fetal scalp blood sampling: A prospective randomized study. British Journal of Obstetrics and Gynaecology, 105, 29-33. http://dx.doi.org/10.1111/j.1471-0528.1998.tb09346.x

[35] Baldari, C.B.V., Emerenziana, G.P., Gallotta, M.C., Silva, A.J. and Guidetti, L. (2009) Accuracy, reliability, linearity of Accutrend and Lactate Pro versus EBIO plus analyser. European Journal of Applied Physiology, 107, 105111. http://dx.doi.org/10.1007/s00421-009-1107-5

[36] Allen, R.M.B.F. and Oats, J.J. (2004) Determining the fetal scalp lactate level that indicate the need for intervention in labour. Australian and New Zealand Journal of Obstetrics and Gynaecology, 44, 549-552. http://dx.doi.org/10.1111/j.1479-828X.2004.00306.x

[37] Luttkus, A.K.F.C., Sehouli, J., Stupin, J. and Dudenhausen, J.W. (2010) Technical performance of lactate biosensors and a test-strip device during labour. Zeitschrift fur Geburtshilfe und Neonatologie, 214, 62-67. http://dx.doi.org/10.1055/s-0030-1249641 